\title{
Música y conflicto armado: representaciones de identidad, memoria y resistencia en el compilado musical "Tocó cantar: una travesía contra el olvido"*
}

MUSIC AND ARMED CONFLICT: REPRESENTATIONS OF IDENTITY, MEMORY AND RESISTANCE IN THE MUSICAL COMPILATION "TOCÓ CANTAR: UNA TRAVESÍA CONTRA EL OLVIDO"

MÚSICA E CONFLITO ARMADO: REPRESENTAÇÕES DE IDENTIDADE, MEMÓRIA E RESISTÊNCIA NA COMPILAÇÃO MUSICAL "TOCÓ CANTAR: UNA TRAVESÍA CONTRA EL OLVIDO"

\section{Laura Rocío Molina Bohórquez**}

Cuadernos de Música, Artes Visuales y Artes Escénicas

/ Volumen 14 - Número 2 / Julio - Diciembre de 2019

/ ISSN 1794-6670 / Bogotá, D.C., Colombia / pp. 125-145

Fecha de recepción: 12 de diciembre de 2018

Fecha de aceptación: 19 de febrero de 2019

Disponible en línea: 25 de junio de 2019

doi 10.11144/javeriana.mavae14-2.myca

* $\quad$ Este artículo se deriva de la tesis de pregrado, que lleva el mismo título, realizada entre 2016 y 2017.

* Maestra en Música con énfasis en musicología por la Pontificia Universidad Javeriana.

ORCID 0000-0002-1843-8401.

\section{Cómo citar:}

Molina Bohórquez, Laura Rocío. 2019. "Música y conflicto armado: representaciones de identidad, memoria y resistencia en el compilado musical 'Tocó cantar: una travesía contra el olvido'." Cuadernos de Música, Artes Visuales y Artes Escénicas 14 (2): 125-145. http://doi.org/10.11144/javeriana.mavae14-2. myca 


\section{Resumen}

El objetivo principal de esta investigación fue analizar las representaciones de identidad, memoria y resistencia presentes en el compilado musical de cuarenta y cinco canciones Tocó cantar: una travesía contra el olvido de 2015 producido por el Centro Nacional de Memoria Histórica y así explorar la complejidad de la relación música-conflicto armado. Mediante un análisis del discurso - basado en la semiótica de Charles Sanders Peirce- se estudió la construcción de sentido generada por la relación entre las letras y los materiales sonoros no verbales de las canciones. La dimensión cultural del compilado se incorporó a la investigación por medio de la realización de cuarenta y cinco entrevistas con personas involucradas en la preproducción, producción y difusión del compilado. Finalmente, en dos grupos focales, se indagó su recepción y la relación entre su dimensión visual (librillo) y sonora. Se concluyó que las representaciones de identidad, memoria y resistencia derivadas del compilado son diversas y en algunos casos complejizan las simplificaciones que promueven los discursos difundidos acerca del conflicto armado. Por otra parte, la relación entre las letras, lo sonoro no verbal y la dimensión visual son esenciales para la construcción de significados y para las representaciones de memoria, identidad y resistencia. Por tanto, contrario a lo que se planteó en el momento de hacer la convocatoria para el compilado y lo que proponen investigaciones similares (que se han enfocado en el análisis de las letras y en las dimensiones políticas, culturales e históricas en que se desarrollan las canciones), la dimensión sonora no verbal cumple un papel fundamental en la construcción de sentido y en su recepción.

Palabras clave: música; conflicto; memoria histórica resistencia; identidad

\section{Abstract}

The main purpose of this research was to analyze the representations of identity, memory and resistance present in the 2015 musical compilation of forty-five songs titled Tocó cantar: una travesía contra el olvido, produced by the Centro Nacional de Memoria Histórica and thus explore the complexity of the relationship between music and the armed conflict. Through an analysis of discourse - based on the semiotics of Charles Sanders Peirce - the construction of meaning generated by the relationship between the lyrics and the non-verbal sound materials of the songs was studied. The cultural dimension of the compilation was incorporated into the research through forty-five interviews conducted with people involved in the preproduction, production and dissemination of the compilation. Finally, the reception of the compilation and the relationship between its visual dimension (booklet) and sound were researched in two focus groups. It was concluded that the representations of identity, memory and resistance derived from the compilation are diverse and in some cases complicate the simplifications promoted by the disseminated discourses about the armed conflict. Furthermore, the relationship between the lyrics, non-verbal sound and the visual dimension are essential to build meanings and for the representations of memory, identity and resistance. Therefore, and contrary to the suggestion made when the call for compilation first went out and to what similar researches (which focused on analyzing the lyr ics and the political, cultural and historical dimensions in which the songs take place) propose, the nonverbal sound dimension plays a fundamental role in the construction of meaning and its reception

Keywords: music; conflict; historical memory; resistance; identity.

\section{Resumo}

O objetivo principal desta pesquisa foi analisar as representações de identidade, memória e resistência presentes na compilação musical de quarenta e cinco músicas, Tocó cantar: una travesía contra el olvido, de 2015, produzida pelo Centro Nacional de Memória Histórica e, assim, explorar a complexidade do relacionamento entre conflito armado e música. Através de uma análise do discurso - baseada na semiótica de Charles Sanders Peirce - estudou-se a construção de significados gerados pela relação entre as letras e os materiais sonoros não verbais das canções. A dimensão cultural da compilação foi incorporada à pesquisa por meio da realização de quarenta e cinco entrevistas com pessoas envolvidas na pré-produção, produção e disseminação da compilação. Finalmente, em dois grupos focais, a recepção da compilação e a relação entre sua dimensão visual (folheto) e do som foram investigadas. Concluiu-se que as representações de identidade, memória e resistência derivadas da compilação são diversas e, em alguns casos, dificultam as simplificações promovidas pelos discursos disseminados sobre o conflito armado. Por outro lado, a relação entre as letras, o som não verbal e a dimensão visual são essenciais para a construção de significados e para as representações de memória, identidade e resistência. Portanto, ao contrário do que foi proposto no momento da convocação para a compilação e do proposto em pesquisas similares (que se concentraram na análise das letras e dimensões políticas, culturais e históricas nas quais se desenvolvem as canções), a dimensão sonora não verbal desempenha um papel fundamental na construção do sentido e na sua recepção.

Palavras-chave: música; conflito; memória histórica; resistência; identidade. 


\section{INTRODUCCIÓN}

El compilado musical Tocó cantar: una travesía contra el olvido fue producido en 2015 por el Centro Nacional de Memoria Histórica (CNMH). Esta, como otras de sus producciones musicales, por ejemplo Las voces de El Salado (2011), Les voy a cantar la historia (2013), Cantos del Carare (2014) y Las musas de Pogue (2015), son iniciativas de recolección de memoria histórica sobre el conflicto armado colombiano, materiales que pretenden contribuir a la reparación integral de las víctimas del conflicto, como se estipula en la Ley 1448/2011, de junio 10.

Estos fueron los primeros discos que escuché acerca del conflicto. No fue una tarea sencilla, sin embargo, considero que hablar sobre el disco no es suficiente. Por esta razón, me gustaría invitar a quien esté leyendo este artículo a acompañar su lectura con la escucha de las canciones, ya sea utilizando el enlace que aparece en este pie de página ${ }^{1}$ o el siguiente código QR para acceder a los audios (figura 1).

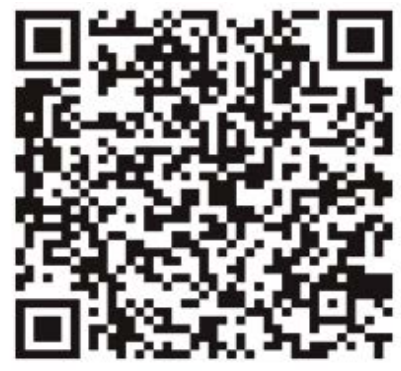

Figura 1. Código QR de escucha Tocó cantar en SoundCloud. Fuente: Elaboración propia.

Plantear iniciativas de recolección de memoria a través del arte no es un trabajo sencillo. Tanto el proceso de creación de estos proyectos como sus resultados merecen ser pensados a fondo y de manera crítica. Es necesario ir más allá de la idea, ampliamente difundida, de que el papel de la música en contextos de violencia se reduce a ser un instrumento para construir paz y reconciliación. La música, como objeto sonoro y como práctica, está atravesada por relaciones, discursos e intereses diferentes que pueden entrar en conflicto.

Para tener un atisbo de la complejidad del papel de la música en el conflicto, se estudió el compilado musical mencionado considerando su dimensión sonora y cultural. Se utilizaron tres categorías principales para analizarlo: las representaciones de identidad (las diferentes lecturas propuestas de identidades individuales y colectivas), las representaciones de memoria (recolectar memoria del conflicto fue el principal objetivo del $\mathrm{CNMH}$ al realizar el compilado) y las representaciones de resistencia. Se analizaron las canciones y el librillo del disco (en sus dos versiones), y se realizaron entrevistas con las personas que participaron en la preproducción, producción, difusión y recepción del compilado. 


\section{EL COMPILADO: CONVOCATORIA, PREPRODUCCIÓN, PRODUCCIÓN Y POSPRODUCCIÓN DEL DISCO}

El compilado Tocó cantar fue resultado de la II Convocatoria de Propuestas Artísticas y Culturales de Memoria realizada en 2014. La convocatoria invitaba a cualquier persona a nivel nacional (no era necesario presentar un registro único de víctimas) a enviar "líricas" sobre memoria del conflicto armado. Hubo cuarenta y cinco ganadores que recibieron un reconocimiento económico y la preproducción, producción, posproducción y difusión de su canción en el compilado musical.

El CNMH decidió pedir solo las letras de las canciones para evitar que la falta de herramientas de grabación impidiera la participación de las personas. La segunda razón fue la ventaja que, según ellos, suponía conocer el contenido de las letras. Así lo ilustra la siguiente cita de Andrea Maldonado, coordinadora del proyecto del CNMH: "Habíamos pensado que era más fácil producir un $C D$ teniendo las líricas ya, porque ritmos hay muchos, pero la letra es muy particular" (comunicación personal, 2-3 de marzo de 2017).

En esta comunicación personal, es posible ver que la dimensión no verbal de las canciones (música, instrumentación, inflexiones de la voz, samples) fue entendida desde el planteamiento de la convocatoria como un elemento subordinado a la letra y de alguna manera accesorio. Sin embargo, al hablar de construcción de memoria a través de canciones, es importante entender lo musical como una relación entre lo verbal y lo no verbal que genera un entramado que transmite sentido.

\section{LOS JURADOS}

Uno de los principales retos a los que se enfrentaron los jurados — dos de ellos músicos externos al CNMH y un jurado del $\mathrm{CNMH}$, artista escénica - para escoger a los ganadores fue encontrar parámetros objetivos para seleccionarlos. Fue muy difícil escoger solo cuarenta y cinco ganadores, en primer lugar, porque todas las canciones que llegaron construían memoria del conflicto armado, y en segundo lugar, debido a que las canciones que llegaron estaban en diferentes etapas de producción (hubo desde letras escritas a mano en hojas de cuaderno hasta canciones grabadas profesionalmente acompañadas de partitura), lo que hizo imposible compararlas y basarse en la calidad musical (producción, composición, etc.) como un parámetro para seleccionar a los ganadores. Después de reflexionar, estos fueron algunos de los criterios escogidos por los jurados:

- Darles prioridad a quienes tuvieran menos posibilidades de grabar y producir sus canciones.

- Distribuir el dinero del premio en las diferentes regiones del país.

- Escoger no solo canciones que hablaran del conflicto, sino de aspectos positivos de una región o población.

- No escoger letras de personas que en las canciones se identificaran como victimarios. 
De los puntos anteriores se puede concluir que los ganadores fueron escogidos principalmente por parámetros extramusicales, tales como darles la oportunidad de producir un disco a quienes menos posibilidades tenían para hacerlo y visibilizar la diversidad de lecturas sobre el conflicto. La intención de los jurados de escoger canciones que narraran no solo la crudeza del conflicto sino también los aspectos "positivos" de la gente y sus territorios es una tensión que aparecerá también entre la imagen de la portada del cuadernillo y las letras de las canciones, como veremos más adelante.

La decisión por parte de uno de los jurados de no incluir en el compilado las voces de "victimarios" (entendidos como aquellas personas que se reconocían como responsables de cometer actos violentos en sus letras) evidencia que el conflicto existe, inclusive, en la construcción de memoria. La oposición víctima/victimario, planteada por los jurados, aparece en varias canciones del compilado; sin embargo, en otras canciones, se cuestiona esa polaridad e, incluso, se llega a plantear que los victimarios son víctimas de algún modo.

No incluir las voces de los victimarios en la construcción de memoria puede ser entendido como una forma de violencia simbólica, al ser una manera de negación del otro y del conflicto que se tiene con él. Aquí me parece importante introducir una diferenciación entre los conceptos de conflicto y violencia, que tienen valor no solo como categorías de pensamiento, sino que es fundamental para encontrar una alternativa a la violencia para resolver los conflictos.

Según Rubin, Pruitt y Kim (1994), "el conflicto significa una divergencia de intereses, en la que se cree que las aspiraciones o expectativas de las partes involucradas no pueden ser alcanzadas simultáneamente" (citados en Fry, Kaj y Kaj, 2013, 10; la traducción es mía). Siguiendo la definición anterior, la divergencia de intereses o creencias es una consecuencia esperada de la interacción entre individuos o grupos, y el conflicto es una característica inevitable de la vida en sociedad. Sin embargo, la forma de lidiar con este cambia en cada situación. Algunas formas de manejar el conflicto son:

Negar su existencia (del conflicto), negociar una solución que beneficie a ambas partes, hacer concesiones, amenazar verbalmente, atacar físicamente, recurrir a un tercero que medie, etc. Por tanto, el conflicto no es sinónimo de agresión verbal o física, que puede definirse como hacerle daño o causar dolor (físico, psicológico o social) a otra persona (o grupo). (Fry et al. 2013, 11; la traducción es mía)

Consideramos que tener en cuenta esta diferenciación es esencial para construir memoria, entendiéndola como una matriz donde se insertan memorias diversas que pueden (y van a) entrar en conflicto. Entonces, es fundamental cuestionarse cómo se pueden relacionar estas memorias que entran en conflicto de una manera no violenta.

\section{PRODUCCIÓN Y POSPRODUCCIÓN}

Durante el proceso de producción, se hizo evidente la importancia de entender el compilado como un vehículo de memoria y como un producto musical que funciona bajo unas lógicas y tiempos específicos que deben ser tenidos en cuenta en el momento de plantear un proyecto como este. 
Debido a que los ganadores fueron personas de toda Colombia, por sugerencia de Llorona Records (el sello independiente encargado de la producción y posproducción del compilado), las grabaciones se realizaron en puntos estratégicos alrededor del país.

Lorena Gallego, una de las coordinadoras del proyecto del $\mathrm{CNMH}$, nos contó cómo fue el proceso de producción:

Las canciones estaban en distintas etapas. Había algunas que ya las habían grabado, mezclado y masterizado. Ya estaban listas. Había otras que no. Otras que incluso estaba la letra y no estaba musicalizada, por ejemplo. Entonces, una sugerencia por parte de Llorona fue que las personas de las regiones consiguieran músicos que empezaban a seguirles la idea. O sea, ellos llegaban y apoyaban a la persona ganadora para que musicalizara su canción. Nosotros llegábamos únicamente a grabar. (comunicación personal, 1 de abril de 2016)

Los principales retos con los que se encontraron los ingenieros de sonido en el momento de hacer la producción del compilado fueron escoger equipos de grabación fáciles de transportar e idóneos para grabar distintas músicas, formatos instrumentales y locaciones diversas. También fue un reto lograr la cohesión del sonido de las canciones, por las distintas condiciones en que se hicieron las grabaciones. Sin embargo, el reto más importante fue hacer la grabación y mezcla de las canciones en un tiempo limitado. A pesar de que los ganadores de la convocatoria pudieron decidir qué querían transmitir en su canción, la instrumentación y las técnicas de grabación, debido a los plazos establecidos por el $\mathrm{CNMH}$, la Organización Internacional para las Migraciones (OIM) y la Agencia de los Estados Unidos para el Desarrollo Internacional (USAID), patrocinadores del proyecto, no hubo tiempo para que participaran en la mezcla de sus canciones. Al preguntarle a Julián Gallo, ingeniero de sonido, encargado de la producción y posproducción sobre el proceso de mezcla, esto fue lo que comentó:

Si uno quiere hacer una mezcla buena, se demora más o menos unos dos o tres días por canción (más o menos tres meses para la mezcla de las cuarenta y cinco canciones). Y como el disco fue hecho con recursos de la OIM, la OIM, junto con el CNMH, necesitaba ese disco para tal fecha. Entonces, digamos que no se contó con el tiempo suficiente y nos tocó correr bastante. También es importante valorar el proceso de cómo la música misma va encajando en unas letras. Por ejemplo, a esa fase hay que darle un tiempo, desde que se está formulando un proyecto. Tener en cuenta el tiempo que se demoran en encajar musicalmente las canciones, luego el tiempo de grabación, luego el tiempo de mezcla. Y que se asesoraran por alguien que supiera cómo era el proceso. Entonces digamos que fue un aprendizaje para el $\mathrm{CNMH}$, fue un aprendizaje para nosotros y fue un aprendizaje para todos. (comunicación personal, 14 de marzo de 2017)

Desde el planteamiento de la convocatoria, al darle prioridad a la recolección de letras, no se consideró que las canciones requieren unos procesos, unos tiempos y un trabajo conjunto entre compositores, instrumentistas y productores. Si se quiere entregar un resultado que satisfaga las expectativas de los diferentes actores involucrados, todas estas variables deben ser contempladas en el momento de plantear iniciativas musicales de construcción de memoria. 


\section{LA DIMENSIÓN VISUAL}

Tocó cantar ha tenido dos ediciones hasta ahora. La primera fue publicada en octubre de 2015 y diseñada por Montenegro Studio, que tiene sede en Barcelona, España, fundado por el diseñador gráfico colombiano Juan Pablo Muñoz.

Al comienzo del proceso, Juan Pablo recibió las letras de las canciones, algunos audios y las fotografías de los participantes tomadas durante la grabación de las canciones. Para él la diversidad del compilado fue la característica más sobresaliente, tanto por la cantidad de géneros musicales como por la variedad de lugares de procedencia de los autores. Como se ve en la figura 2, para retratar esta diversidad en el librillo del compilado, decidió poner el título de cada canción en una tipografía distinta y usar los colores de la bandera de Colombia en tonos pastel.

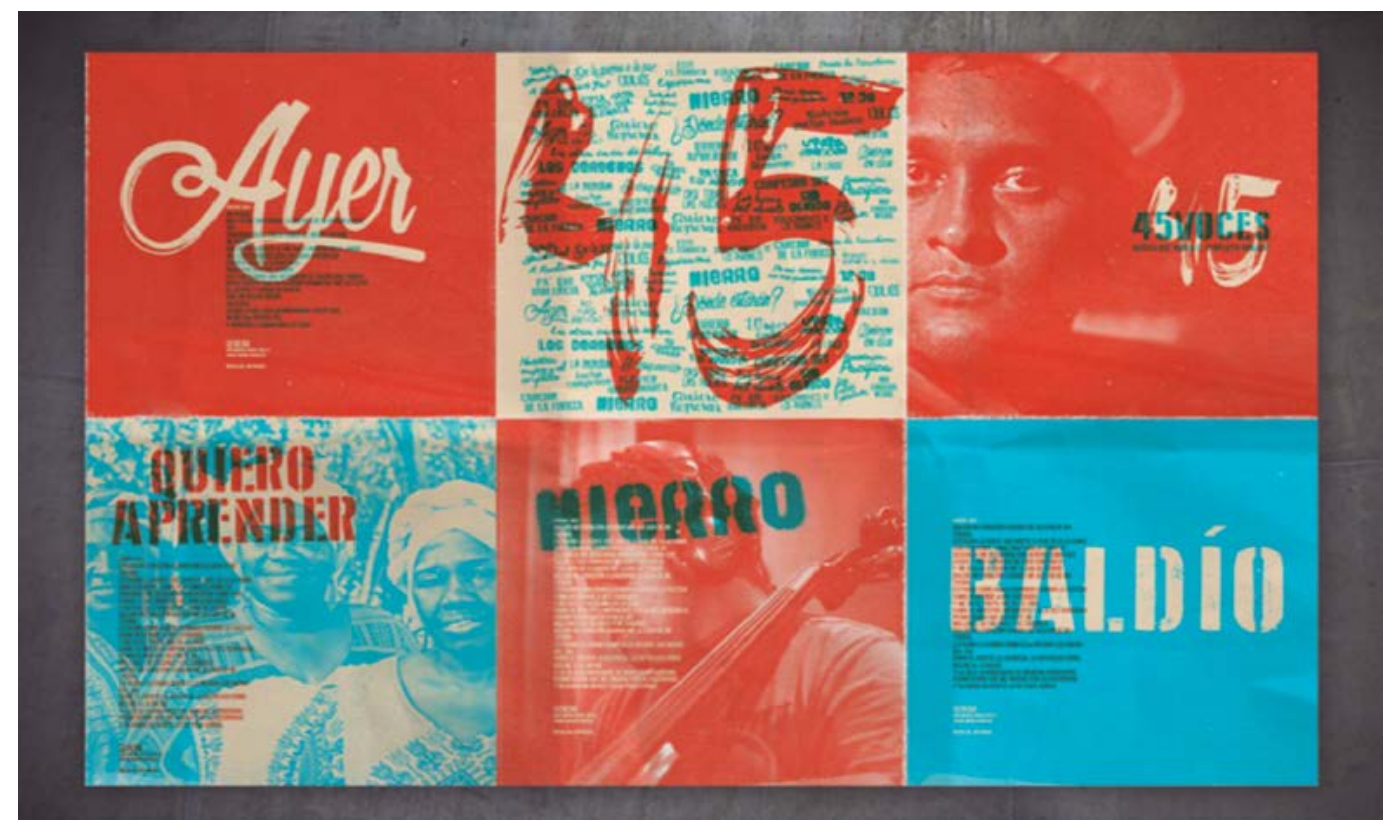

Figura 2. Primera propuesta de arte de Tocó cantar.

Fuente: Juan Pablo Muñoz, Montenegro Studio (2017).

Sin embargo, esta primera propuesta fue rechazada por el $\mathrm{CNMH}$, según Juan Pablo, porque:

les parecía un disco como de rap o como muy street style, y no se sentían muy identificados con él. Estaba muy enfocado como en los géneros modernos que tenía, dejando un poco de lado la parte folclórica que también tiene el disco. Entonces, le dimos la vuelta y cambiamos todo, para que fuera mucho más incluyente, sin perder la esencia de que se viera actual y moderno. (comunicación personal, 7 de marzo de 2017)

Con estas observaciones hechas por el $\mathrm{CNMH}$, Montenegro Studio replanteó la propuesta, utilizando varios estilos de ilustración, colores vivos, flores, aves e instrumentos como el acordeón, la guitarra y el sombrero vueltiao, acompañado del título en letras blancas, como se ve en la figura 3. Al preguntarle a Juan Pablo acerca de la razón de la escogencia de estos elementos, respondió: 
Eran los más significativos, los que la gente iba a entender directamente. Estaba el micrófono, porque la letra era lo más importante del proyecto. La convocatoria era alrededor de las letras y no de la música, porque la música la iban a producir, pues, unos productores. El acordeón, pues, supertípico y la guitarra... digamos que también. Parte del feedback que en el CNMH me daban era que se entendiera muy fácil de qué iba. Entonces, por eso, están esos instrumentos. Cualquier persona va a reconocer que esto va de música. Y respecto al sombrero vueltiao, pues Colombia, ¿no? Es como un símbolo de nosotros, ¿no crees? Cualquier persona lo va a reconocer como algo colombiano. (comunicación personal, 7 de marzo de 2017)

El acordeón y el sombrero vueltiao son íconos importantes, no solo de la música de la Costa Caribe, sino que, como lo mencionó Juan Pablo, se han convertido en símbolos de la "identidad nacional" y de la "música nacional." A este fenómeno de resignificación de la identidad colombiana como un país caribeño se han referido investigadores como Wade (2002).

La representación de Colombia como una nación alegre y caribeña ha venido sucediendo en la música desde el siglo pasado. Investigadores como Hernández hablan del "tópico de la alegría" que se le ha asignado a la música de la Costa Caribe:

La industria musical de la segunda mitad de los años 40 se esforzó por producir música que tuviera un claro mensaje de optimismo nacionalista, al servicio del proceso económico. Esta prioridad dio paso en los años 50 a una preocupación por aumentar el volumen de ventas de la música costeña bailable, algo que se manifestaba en la presión por componer música sencilla, que pudiera asociarse fácilmente con el mito de la Costa Atlántica como un paraíso de felicidad. $(2016,194)$

En el primer grupo focal realizado para esta investigación, se mencionó la similitud entre el título de La tierra del olvido de Carlos Vives (figura 4) y el título del compilado Tocó cantar. Esta similitud se puede extender incluso al uso de elementos visuales comunes para representar lo nacional en sus carátulas: la guitarra eléctrica, el acordeón, la gaita y el énfasis en la diversidad de fauna y flora.

Los colores de la carátula de Tocó cantar también fueron asociados a la campaña "La respuesta es Colombia" (figura 5), cuya canción insignia fue una nueva versión de La tierra del olvido. Esta campaña y su versión original "Colombia es pasión" de 2005 hacen parte de la iniciativa Marca País, que surgió de una alianza entre el Gobierno Nacional y el sector privado, buscando presentar al país como una marca. Con esta iniciativa, se pretendía generar identidad nacional e internacional para promover la inversión de empresas extranjeras en el país, el turismo y la exportación. Estas campañas buscan mejorar la imagen de Colombia en el exterior. Para hacer esto, exaltan la diversidad, la riqueza natural y cultural, intentando dejar de lado los discursos que ligan la identidad nacional con el conflicto armado y el narcotráfico.

Las carátulas de los discos mencionados y la campaña Marca País se insertan en un mismo discurso "idealizado y positivo" de la nación. La carátula del disco de Carlos Vives señala una cercanía al conocimiento ancestral indígena. Sin embargo, esta representación "idealizada" de la nación desconoce los problemas del conflicto armado, la depredación de la naturaleza y el ataque sistemático a las comunidades indígenas. Desde las imágenes que circulan en las industrias culturales, se reproduce este imaginario de nación "positiva, alegre y fiestera" que desconoce e impide la construcción de una memoria crítica sobre el fenómeno del conflicto armado. 


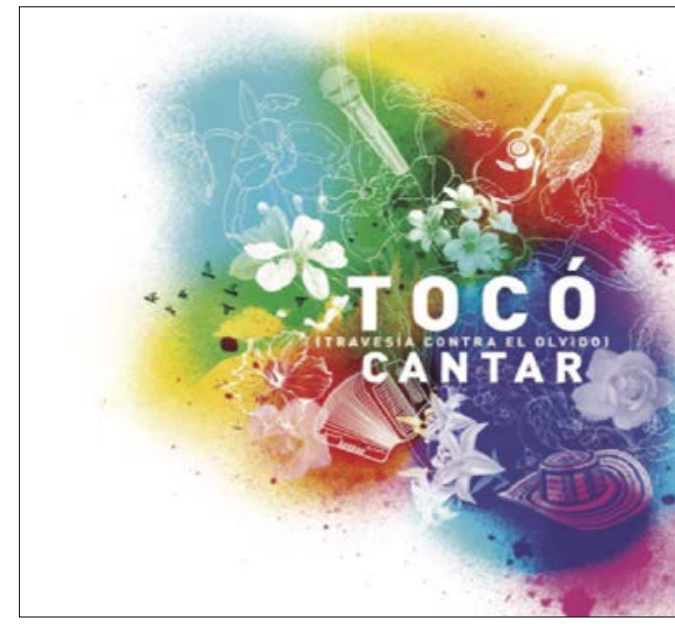

Figura 3. Carátula primera edición Tocó cantar. Fuente: CNMH (2015)

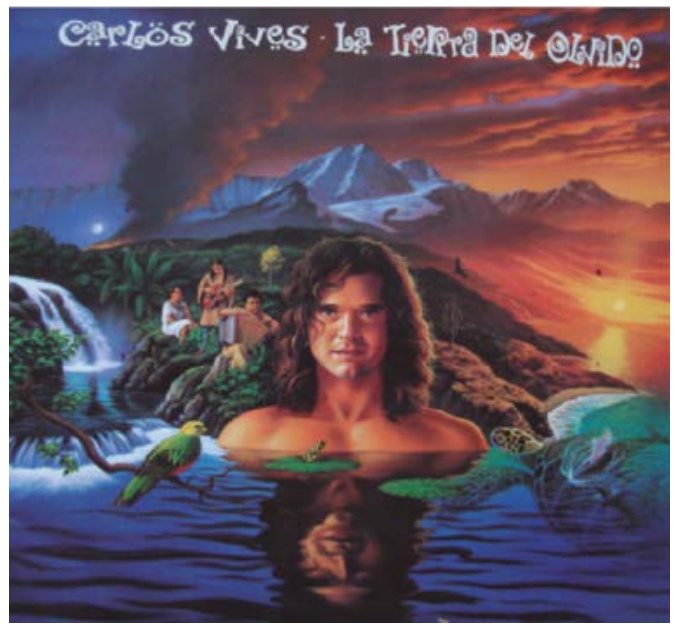

Figura 4. Carátula de La tierra del olvido de Carlos Vives (1995). Fuente: Vives (1995).

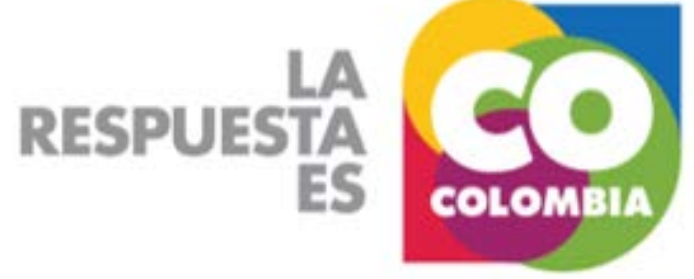

Figura 5. La respuesta es Colombia. Fuente: Naranjo Publicidad (2019).

Al preguntarle a Juan Pablo Muñoz sobre el porqué de la decisión de la imagen de la carátula, respondió:

RESPUESTA: En el CNMH, sentían la primera carátula [figura 1] muy... opaca, no la sentían tan alegre y pues teníamos que representar algo más bonito, lograr representar la diversidad y reflejar lo contrario de lo que reflejaban las letras. Es superduro, porque las letras son, bueno, es lo que ha vivido la comunidad colombiana desde hace cincuenta años. Por eso ellos querían que el arte del disco representara lo opuesto, ¿si me entiendes?

PREGUNTA: ¿Para que fuera más asequible para las personas?

RESPUESTA: No tanto más asequible, sino que empezaran a verlo de otra forma, ¿sí?, como que esto no era seguir ahí victimizándonos. Esto es como "estamos saliendo de esto". (comunicación personal, 7 de marzo de 2017; las cursivas son mías)

El hecho de que a Juan Pablo Muñoz le pidieran representar en el diseño de la carátula "lo opuesto a las letras" contribuye con una construcción de memoria del conflicto armado que intenta ser "positiva", ya que se enfoca en "dejar de victimizarnos" y promover el mensaje "ya estamos saliendo del conflicto".

Esta postura puede tener que ver con la necesidad del CNMH de no solo recoger memoria sobre el conflicto armado, sino de intentar que esta memoria contribuya con la construcción de paz y la no repetición. Como afirma Ritter: 
El modelo de todas las comisiones de verdad está basado en dos suposiciones que usualmente se contradicen: en primer lugar, hacer un recuento del pasado más profundo y "verdadero" en contraposición a actos previos de distorsión, silenciamiento y omisión; y en segundo lugar, que este conocimiento de la verdad sirva como la base para una reconciliación nacional y la construcción de ese nuevo futuro imaginado colectivamente. (2012, 4; la traducción es mía)

Sin embargo, esta carátula, al usar los mismos códigos visuales que han sido empleados para ocultar y silenciar las violencias y el conflicto en general (lo que hace muy difícil intentar cambiar el sentido de estos elementos visuales), hace que aquella pueda ser interpretada como una reproducción del mismo discurso de ocultamiento.

La segunda edición del compilado (figura 6) fue publicada en abril de 2016. El cuadernillo de esta segunda edición cuenta con fotografías de los ganadores e ilustraciones realizadas por Jovanny Galeano Muñoz durante la grabación, lo que le da más protagonismo a los artistas de la convocatoria.

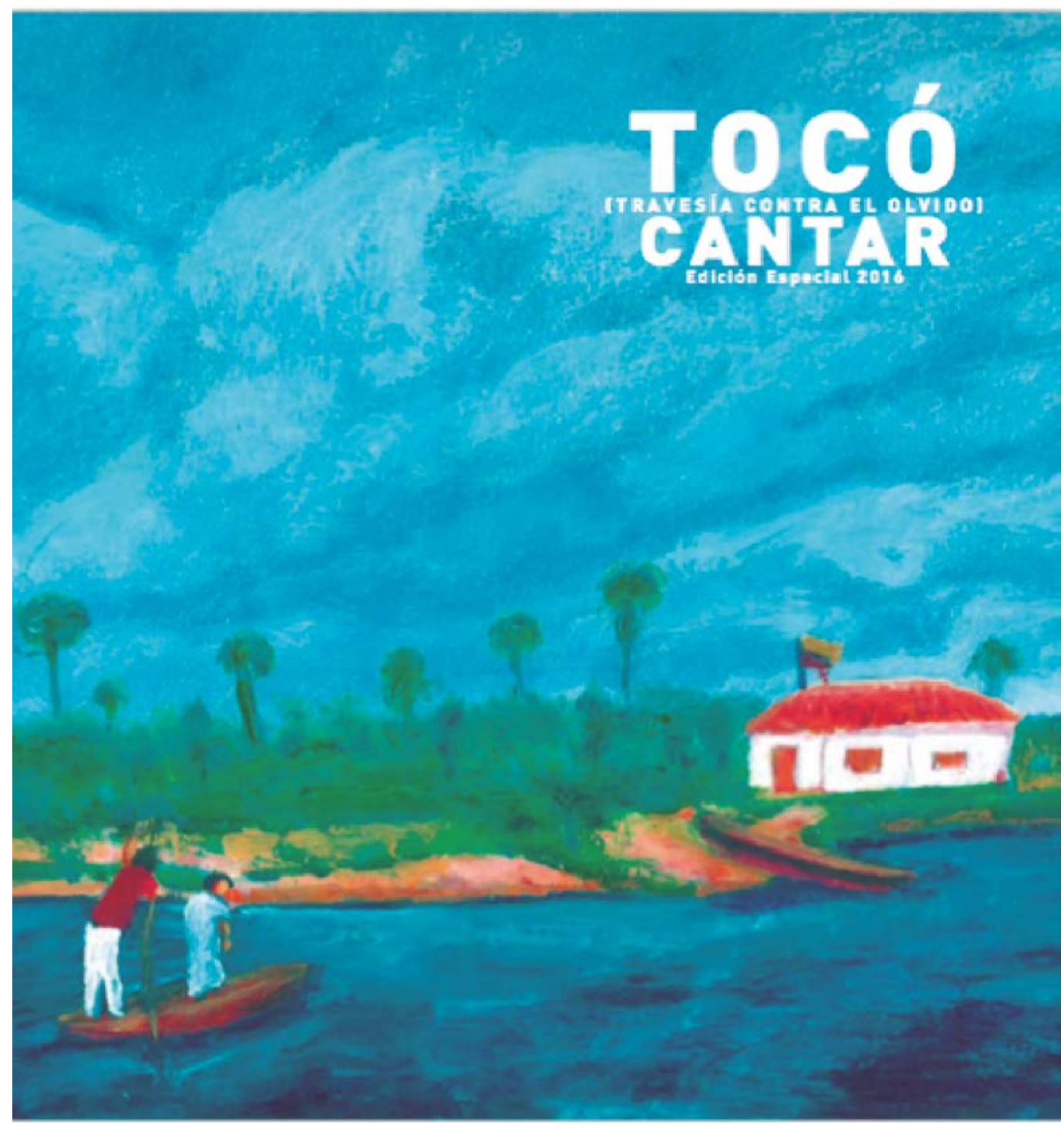

Figura 6. Carátula de la segunda edición del compilado Tocó cantar. Fuente: CNMH (2016) 
Al presentar esta carátula al segundo grupo focal, los participantes la asociaron principalmente a un contexto rural y a músicas tradicionales. Cinco de los doce participantes encontraron relación entre esta imagen y el conflicto armado, probablemente debido a que los elementos rurales entran dentro del estereotipo de conflicto armado que se ha reforzado históricamente.

\section{ANÁLISIS DE LAS CANCIONES}

En la construcción de sentido de las canciones, coexiste la carga semiótica de lo sonoro verbal y lo no verbal: la letra, las inflexiones, la dicción y el timbre de la voz, el uso de samples, el modo, la tonalidad, el ritmo, la instrumentación, la progresión armónica, el uso de efectos de sonido, etc. Todos estos elementos en relación generan lo que Turino $(2014,189)$ llama "densidad semiótica", con lo que se refiere a "la gran cantidad de signos que operan potencialmente juntos en cualquier medio" y que son susceptibles de reforzar un mensaje o contradecirlo.

Como se puede ver en la tabla 1, para comenzar el análisis dividimos las canciones del compilado en tres grandes grupos, de acuerdo con el nivel de mediación del evento violento que narraban en sus letras ${ }^{2}$. Desde una perspectiva semiótica, mediación hace referencia a la cantidad de signos posibles que intervienen entre la experiencia directa de un hecho violento y la transformación de este en memoria. Cuando alguien sufre un evento violento directamente, su relación con la experiencia está únicamente mediada por su capacidad de recordar. Sin embargo, para que alguien conozca un evento violento que no vivió, existen más signos de por medio: recibe un enunciado que no solo está mediado por la memoria de quien lo transmite, sino por cómo lo interpreta.

\section{TABLA 1. CLASIFICACIÓN DE LAS CUARENTA Y CINCO CANCIONES POR NIVEL DE MEDIACIÓN EN LAS LETRAS}

\begin{tabular}{|c|c|c|}
\hline Grupo 1 & Grupo 2 & Grupo 3 \\
\hline Masacre en Sonora & No más abuso & De la guerra a la paz \\
\hline Salida & El desplazamiento de los animales & Pa'qué violencia \\
\hline Bojayá masacre y olvido & Desde la trinchera & Resistencia pacífica \\
\hline Desaparecido & Exilios & Patria en marcha \\
\hline Ahí estás & ¿Dónde estarán? & Tu quieres tierra Gimieron \\
\hline los días
\end{tabular}




\begin{tabular}{|c|c|c|}
\hline Sin olvido & Ayer & A reclamar ya \\
\hline Falsos positivos & Baldío & Saquen banderas de paz \\
\hline Un lider embera & Esta casa tuvo una alegría & Pacífico gran comarca \\
\hline Mu embera wera & Espérame & Un rio que canta \\
\hline Aquí te espero & & ¿Por qué recordar? \\
\hline Historia de la Pachamama & & La memoria \\
\hline Casi todas las noches & & \\
\hline De mi tierra no me quiero ir & & \\
\hline Campesino soy & & \\
\hline $12: 30$ a. m. & & \\
\hline Lalinde & & \\
\hline Quiero regresar & & \\
\hline Diez años cada domingo & & \\
\hline Los derechos & & \\
\hline
\end{tabular}

Fuente: Elaboración propia.

El primer grupo contiene letras que asemejan un testimonio. Idealmente están escritas en primera persona (singular o plural), tratan un hecho violento concreto (masacre, desaparición, asesinato, desplazamiento) de manera explícita y detallada, no utilizan lenguaje metafórico o poético, y presentan fechas y nombres propios de los lugares o personas involucradas en él. Todos estos elementos dan, desde lo verbal, una sensación de menor mediación entre el evento violento y la persona que canta la canción.

En el segundo grupo, las canciones se refieren a un fenómeno de violencia (desplazamiento, desaparición, violencia contra la mujer, etc.) y no a casos puntuales, es decir, rastreables durante la escucha de la canción. No hay nombres propios de personas o lugares, y pueden contener lenguaje poético y metafórico. Se enfocan más en las emociones y pensamientos del narrador que en contar lo sucedido.

Finalmente, en el tercer grupo, las canciones hablan sobre memoria y conflicto armado en general o son una exhortación a acciones de resistencia en general. Hacen uso de lenguaje metafórico y casi siempre están escritas en presente. 
La semiótica musical ha demostrado que los elementos sonoros no verbales tienen una forma de significación propia. Por ejemplo, cuando la canción Mu embera wera de Yajaira Murry Murri fue presentada a los grupos focales, dado que está en embera y que ninguno de los participantes podía comprender la letra, lo sonoro no verbal fue fundamental para la construcción de sentido. Como se puede ver en la siguiente cita, el formato instrumental funcionó como un ícono (parecido en sus características) de la precariedad en la que viven algunos desplazados en la ciudad:

El sonido de la guacharaca y las voces indígenas, porque puede que uno no esté entendiendo lo que están diciendo por el lenguaje, pero la voz, el tono, el instrumento, te dice mucho. Por ejemplo a mí esa canción me remitió a unos indígenas que están en el puente de la 106 con autopista [Bogotá], en la estación [de Transmilenio, están con la guacharaca, dos niñitos y la mamá. (comentario registrado en el grupo focal conducido por la autora el 17 de febrero de 2017 en la Pontificia Universidad Javeriana)

En la dimensión sonora no verbal, pueden producirse también diferentes niveles percibidos de mediación. Por ejemplo, cuando los materiales musicales son muy complejos (p. ej., melodías elaboradas, texturas densas, etc.), se dificulta entender lo que sucede con cada elemento, y esto produce una sensación de mayor mediación.

En este punto, quisiéramos detenernos para explicar el papel que cumple la voz como elemento determinante en la percepción de mediación de las canciones. En el momento de escuchar una canción, los elementos no verbales de la voz, tales como el timbre y las inflexiones, le permiten al oyente imaginar características del cantante como edad, sexo, lugar de procedencia o incluso nivel educativo. Estas características imaginadas pueden o no coincidir con el estereotipo de víctima del conflicto armado que el oyente tiene en la cabeza y, por tanto, basado en la escucha de estos elementos sonoros, atribuirle un nivel de mediación, es decir, una menor o mayor cercanía con el evento violento que narran, e inclusive un nivel de autenticidad al discurso.

Este fenómeno se hizo evidente en las conversaciones que surgieron en el segundo grupo focal, compuesto mayoritariamente por músicos, donde la mediación y la autenticidad atribuida a las canciones se vio afectada por la voz de los cantantes y por el nivel de producción de las canciones:

A: La duda es cuál es la historia detrás de las canciones y quién es el que está cantando. Nunca sé si la persona vivió eso o no. Me esperaba encontrar algo diferente en la música. A veces me parece muy limpia. Hay por ahí dos canciones que sí siento que es la gente que ha vivido esto y como que coge su guitarra. A veces no, era raro, como si estuviera el mensaje pero cantado por otras personas. Seguramente son los mismos, pero no sé, la manera en que está grabado, no sé...

C: ¡A mí me pasó lo mismo! Quién sabe si tal vez, por cosas que me habías dicho antes, yo me imaginaba algo, no en los géneros musicales, sino en la forma de la presentación del disco. Me imaginaba algo diferente, no me lo imaginaba tan producido, no sé si por creer que era del campo entonces como que creía que era gente que no tenía ninguna formación. Me imaginaba otro tipo de cosa mucho menos producida. (comentarios registrados en el grupo focal conducido por la autora el 17 de febrero de 2017 en la Pontificia Universidad Javeriana) 
En ambos grupos focales se construyó un estereotipo de víctima del conflicto como una persona que viene de un contexto rural, que no ha tenido formación académica, que vive en condiciones precarias y que por tanto suena de una manera determinada. Fue muy interesante ver que en cada grupo focal hubo una persona que se consideraba víctima, que pasó desapercibida para el resto del grupo, por no encarnar las características mencionadas.

Otra dimensión que contribuye con la construcción de sentido en las canciones son las asociaciones entre materiales musicales y emociones construidas históricamente. Como se mencionó en la sección del análisis visual, se han construido tópicos alrededor de ciertas regiones y de sus expresiones culturales, como el tópico de la "alegría" de la Costa Atlántica (Hernández 2016, 54). Gracias a estas, cuando los participantes de los grupos focales escucharon algunas canciones de la Costa Atlántica o de la Costa Pacífica, sintieron una contradicción entre los materiales sonoros no verbales que les producían una sensación afirmativa, festiva o tranquila, y las letras que trataban explícitamente un hecho violento que les generó tristeza, rabia o dolor. Esto fue lo que algunos participantes manifestaron al respecto:

Yo me imaginaba algo superdramático. Una música muy triste, como muy acorde con las historias y las letras. Pero me gustó mucho porque era todo lo contrario, o sea, era un contraste muy grande, como mucha música tranquila, me hacía sentir bien, me daban ganas de bailar y todo, y las historias por debajo, pues, son muy fuertes. (comentario registrado en el grupo focal conducido por la autora el 18 de febrero de 2017 en la Pontificia Universidad Javeriana)

Asimismo, la construcción de tópicos positivos alrededor de estas músicas contribuye a reducir las funciones que los participantes de los grupos focales creían que podían llegar a tener estas músicas en sus contextos locales (donde son medios de expresión de cualquier suceso, en este caso el conflicto), como se puede ver en la siguiente cita:

La escucha me pareció superincoherente. Lo que a mí me produce el folclor y todo lo de mi tierra... Es como si quisiera escuchar la música y la letra la quisiera borrar. Realmente yo escucharía el CD sin letra, porque era como ¡Eh! ¡Wepa je! Baila. Nos están masacrando, nos están matando. No, jo sea no! (comentario registrado en el grupo focal conducido por la autora el 18 de febrero de 2017 en la Pontificia Universidad Javeriana)

Por otra parte, los elementos sonoros no verbales de las canciones también pueden funcionar como íconos de experiencias emocionales humanas. Es decir, como "analogías entre el discurso musical y el proceso dinámico de la emoción" (Hernández 2016, 50-51). Por ejemplo, una canción en un tempo lento, con ritmos largos y una melodía con un registro reducido puede asimilar a la forma de hablar de alguien triste.

La dimensión individual es la última a considerar para analizar la construcción de sentido de las canciones. Esta es la más diversa y difícil de estudiar, ya que tiene que ver con las experiencias particulares que nos llevan a vincular cierta música con determinadas emociones y contextos. 
Considerando los conceptos y las dimensiones que acabamos de revisar, presentamos a continuación el análisis de la primera canción de cada grupo como ejemplo del trabajo que se realizó con todas las canciones del compilado. Invito al lector, una vez más, a escuchar las canciones para acompañar la lectura del análisis.

\section{GRUPO 1: “MASACRE EN LA SONORA” DE JOSÉ ANCÍZAR CANO (TRUJILLO, VALLE DEL CAUCA)}

Esta canción es una carrilera en mi mayor, a cuya progresión tonal sencilla y ritmo de la introducción podría asignársele una valencia positiva; sin embargo, este género musical ha estado asociado a temas de despecho o a la narración de eventos de una manera exagerada, casi tragicómica. El hecho de que la melodía y armonía sea sencilla y fácil de recordar le da más importancia a la voz y a la letra. El timbre de la voz hace pensar en alguien mayor, probablemente de procedencia campesina; esta idea se puede ver reforzada por la pronunciación de palabras como exigir, donde el sonido de la equis se reemplaza por el sonido de la ese, o en la palabra encontramos donde se reemplaza el sonido de la e por el de la i, manera de hablar asociada a la gente del campo.

La Sonora es una vereda del municipio de Trujillo, al norte del departamento de Valle del Cauca. Lo que se conoce como la Masacre de Trujillo son los hechos reconocidos por el Estado, que se presentaron entre el 29 de marzo y 19 de abril de 1990, lo que coincide con las fechas de la desaparición de la que se habla en la letra. Sin embargo, las víctimas piden el reconocimiento por parte del Estado y relacionan este evento con una serie de hechos violentos que sufrieron entre 1986 y 1994. En esta canción, tanto lo verbal como lo musical refuerzan la idea de que hay muy poca mediación entre la persona que canta y el hecho que narra; podría ser entendida por quien la escucha como un testimonio.

\section{GRUPO 2: “NO MÁS ABUSO” DE NURYS ONEYDA ANGULO (TUMACO, NARIÑO)}

Esta letra está escrita en tercera persona, en presente, no hace uso de lenguaje poético, no tiene referencia de tiempo o lugar específicos; sin embargo, al observar la forma en que están escritos los versos que se alternan con el estribillo, se puede relacionar con la forma en que funcionan los alabaos en la Costa Pacífica que también alternan versos y estribillo.

La música en este caso hace una clara adscripción de lugar. Es una juga tocada por un ensamble de marimba, que remite al oyente al sur de la Costa Pacífica. Es un sonido que puede ser interpretado como tradicional, ya que la marimba no está temperada dentro del sistema de afinación proveniente de la música europea occidental. El canto también está dentro de esta afinación particular, las voces de los coros responden al unísono y no a varias voces como en los arreglos que se hacen en versiones de música de la Costa Pacífica que ha sido más producida. Tiene un tempo lento, la melodía de la marimba está basada en la melodía que hace la voz y no hay muchas variaciones rítmicas en los cununos o el bombo, lo que le da importancia a la cantante. 
Inflexiones como el quiebre de la voz y el uso de voz de pecho similar al grito, junto con el salto en la melodía de las palabras en cursivas "están matando a los niños por qué mi Dios, Dios mío que pare esto mi Señor", refuerzan la sensación de reclamo y de desesperación. La posición de defensa de los niños se refuerza con la inflexión de la voz casi hablada en la parte que dice "Que vivan los niños, no más violencia, respetar la vida de los niños... que vivan los niños". Lo musical y lo sonoro dan no solo una clara adscripción de lugar, sino que la voz representa una fuerte presencia de la corporalidad, lo que logra generar una sensación de menos mediación entre lo que se expone en la letra y la experiencia de quienes hacen la música.

\section{GRUPO 3: “DE LA GUERRA A LA PAZ” DE SIMEÓN NOGUERA MAYORGA (BOGOTÁ)}

Escrita en primera persona del plural, habla sobre la historia del conflicto armado, no trata de un caso específico, sino que ofrece valoraciones sobre hechos generales. Hace una referencia de lugar a la región de los Llanos. La construcción de los versos, la rima y el género musical utilizado, un joropo, junto con el formato instrumental, refuerzan esta adscripción de lugar. El uso de la música tradicional de una región principalmente rural puede contribuir a reforzar la percepción de menor mediación con el hecho violento, siguiendo el estereotipo de víctima mencionado. Tiene un tempo rápido y está escrita en tonalidad menor. El uso del género joropo para hablar del conflicto desde lo macro es muy efectivo, ya que al no tener coros hace que se transmita una mayor cantidad de información en las estrofas.

En cuanto a temporalidad, delimita el conflicto armado dentro de los tiempos promovidos por el discurso más ampliamente difundido, que data sus orígenes aproximadamente en la década de 1960, momento en el que se conformaron las Fuerzas Armadas Revolucionarias de Colombia (FARC). El problema de esta delimitación temporal es que se puede caer en no hacer una conexión de este fenómeno con la situaciones de violencia, de desigualdad e injusticia que se venían presentando desde antes en el país (CNMH 2013).

Al referirse al conflicto, en la letra, al igual que pasa en la mayor parte de noticias sobre este tema, aparece información acerca de las consecuencias del conflicto, pero no se refiere a las causas directamente. Hace uso de conceptos como narcotráfico, corrupción y falta de justicia, que son ampliamente usados, pero vaciados de contenido y despolitizados, ya que no vienen acompañados de casos y responsables puntuales.

Asimismo, concluye reduciendo el conflicto a una "guerra fratricida" basada principalmente en el odio y se refiere a ir de "la guerra a la paz", como si la resolución del conflicto se redujera a pasar de un estado a otro, sin profundizar en el cómo.

Una visión reduccionista, simplista e, incluso, maniqueista, que pertenece al discurso hegemónico del conflicto armado, en cuanto que es la visión más difundida entre los colombianos y tal vez la más ampliamente compartida en la actualidad, donde el conflicto se resume en dicotomías como "guerra y paz", "terrorismo y Estado", "buenos y malos" (cfr. Barbero 2005). Este tipo de simplificaciones han contribuido a la polarización del país, al desconocimiento y a la falta de reflexión por parte de la mayoría de la población sobre las causas que siguen alimentando el conflicto. Esta canción hace una crítica del conflicto desde el mismo régimen de enunciación que evita complejizar. 
En síntesis, la construcción de sentido a partir de las canciones es el resultado de la interacción de las letras, la dimensión visual y los materiales sonoros no verbales, que se encuentran con las construcciones individuales, sociales, históricas, culturales y políticas que se han hecho alrededor de estos elementos.

\section{DIFUSIÓN Y RECEPCIÓN DEL COMPILADO}

En esta sección, trataré un aspecto más que es fundamental para comprender el compilado como movilizador de memorias, identidades y resistencias: la música como práctica, como acción.

El hip-hop (el género que más aparece en el compilado), según las entrevistas realizadas con los artistas, más que un género musical debería ser entendido como un estilo de vida que proporciona alternativas para afrontar el conflicto desde el arte. En comunicación personal con Milton Caicedo, integrante de Los Pesados de Colombia, podemos ver cómo han usado el hip-hop para resolver problemas reales en sus comunidades como las "barreras invisibles":

En Buenaventura la manera de romper las barreras fue a través de Súmate al arte por la paz, que fue algo que nosotros hicimos y le incluimos Tapao y paz: un tapao de pescado, vamos a cantar por la paz al barrio tal. Porque allá no se puede pasar. Te pongo un ejemplo: hay dos barrios, aquí está San Luis y aquí Juan XXIII que están pegados. Entonces de esa esquina tú no puedes pasar a la esquina de acá, porque ya el de allá te pega tu tiro, te mata. Entonces pasar de un barrio a otro es difícil, la única forma que nosotros logramos entrar a esos barrios en Buenaventura fue con Súmate al arte y con el hip-hop con los barriales y con Tapao y paz. Vamos a hacer un evento. Listo, una olla comunitaria: entonces allá hay tres artistas, pues, listo, los tres vienen para acá y no hay problema de que los vayan a matar, porque vienen a hacer arte, vienen a cantar. Acá tenemos tres y allá tres. Empezamos a unir todos esos barrios y nos sirvió la iniciativa. No tenemos recursos para hacerlo, pero funciona. $Y$ qué recursos se necesitan para eso, $\$ 500$ 000, que es un bafle que no tenemos (comunicación personal, 6 de febrero de 2017)

En Buenaventura, la música ha permitido a esta comunidad crear dinámicas alternativas a la violencia para solucionar los conflictos. Es importante que se reconozcan y apoyen estas iniciativas que surgen de las comunidades, ya que ellas conocen de primera mano los problemas que los afectan. Aunque es muy valioso grabar y difundir las músicas que se producen en estos contextos, es importante cuestionarse cómo estos proyectos podrían ir más allá de lo sonoro y darles visibilidad a estas prácticas vivas: efectivas para resistir y construir memoria.

Por otro lado, con respecto a las prácticas musicales locales, César López, músico y jurado de la convocatoria, habló sobre las consecuencias negativas del intervencionismo por parte de organizaciones, investigadores o músicos externos a las comunidades: 
Pelados que trabajan en la tierra y una organización cualquiera llega y les dice: Usted es artista. Entonces dice el muchacho: ¿Cómo así, yo soy artista? Entonces yo dejo mi tierra y me voy a buscar camino con la música, porque ya me van a grabar un disco. Y eso me parece terriblemente peligroso [...] se crea sobre esa grabación una gran expectativa. También porque ellos no entienden cuáles son los canales de distribución o de difusión de esas cosas. El señor que está allá se imagina que grabó un disco y que ese disco está en las emisoras, que eso además lo están viendo en todas partes y que es su momento de dejar todo y dedicarse al arte o a la música. (comunicación personal, 21-23 de febrero de 2017)

Este tipo de intervenciones crean expectativas difíciles de cumplir. Las personas ven en las grabaciones, más allá de la posibilidad de expresarse y de repararse, una opción para volverse famosos, que su música sea ampliamente difundida y así alcanzar mejores condiciones de vida. Sin embargo, en las entrevistas realizadas a los ganadores de la convocatoria y a los responsables del $\mathrm{CNMH}$, se hizo evidente que las expectativas de difusión del compilado no se han cumplido.

A pesar de que el CNMH ha adelantado estrategias de difusión, como subir el compilado a la plataforma SoundCloud, donde se puede escuchar gratuitamente, y ha organizado socializaciones y conciertos en varias ciudades del país con algunas de las agrupaciones del compilado, los recursos económicos y humanos destinados a la difusión han sido insuficientes para convertirlo en el producto mediático que se planteó en el proyecto.

Quizá la intención de que el compilado sea un producto articulador de memorias sobre el conflicto armado, heterogéneo y diverso entra en contradicción con la apuesta de convertirlo en producto mediático y ampliamente difundido. Esto se debe, en parte, a que su contenido no responde a las lógicas de difusión y de consumo de las industrias culturales: al incluir músicos no reconocidos, géneros musicales tan variados, letras que no son siempre esperanzadoras y positivas, etc.

Canales alternativos de difusión para este compilado podrían ser explorados. Durante la realización de los dos grupos focales, en los que se escucharon fragmentos de doce canciones del compilado, pudimos notar que la escucha en comunidad generó una serie de reflexiones y acercamientos al conflicto armado que rara vez se dan mediante la lectura de noticias o informes.

En la siguiente cita, se puede ver que la escucha de las canciones permite generar empatía e identificación con el conflicto: "Este CD tiene la ventaja, o personalmente lo sentí, tú escuchas la historia, de la voz de las personas que te imaginas que vivieron eso en primera persona, y eso también genera muchísimo más impacto, más empatía" (comentario registrado en el grupo focal conducido por la autora el 18 de febrero de 2017 en la Pontificia Universidad Javeriana).

\section{CONCLUSIONES}

Desde su dimensión sonora, verbal y no verbal, así como en su dimensión cultural, el compilado Tocó cantar articula diferentes representaciones de identidad, memoria y resistencia. Su diversidad matiza y complejiza los discursos más ampliamente difundidos sobre el conflicto armado en Colombia; sin embargo, entre estos discursos diversos existen tensiones y conflictos. 
Uno de los principales retos para la realización de Tocó cantar fue el interés por parte del CNMH de representar la diversidad de discursos de memoria y, a la vez, la necesidad de escoger a qué darle voz en el compilado. La diversidad entonces no debe ser entendida como absoluta, sino que tiene unos límites que excluyen voluntaria o involuntariamente ciertos elementos.

Esto se evidenció al tener que seleccionar solo cuarenta y cinco canciones para el compilado, a pesar de que todas las canciones que recibieron los jurados construían memoria del conflicto. Asimismo, se manifestó en la decisión de los jurados de no incluir canciones cuyos autores se proclamaran victimarios. Estos discursos, aunque podían enriquecer la diversidad de memorias, fueron invisibilizados. Si estos y los demás discursos entraran en diálogo en vez de ser erradicados, podrían no solo desembocar en una construcción de memoria colectiva, sino que sus dinámicas de diálogo podrían servir como ejemplo de formas no violentas de manejar el conflicto.

A continuación, sintetizo las principales representaciones encontradas en el compilado y las enseñanzas que dejaron los procesos que lo hicieron posible.

Las representaciones de identidad. La escucha de este disco permitió a los asistentes de los grupos focales reconocer que el conflicto armado hace parte fundamental de la identidad colectiva de la sociedad colombiana. La ventaja que tiene la escucha en grupo de estas canciones sobre leer o ver noticias del conflicto armado es que al ser cantado genera una relación más directa con las personas y las historias que narran, y desarrolla en la audiencia un nivel más alto de empatía.

Por otra parte, existen tensiones entre las diferentes representaciones de identidad nacional del compilado. Así, está la representación positiva y alegre de la nación (generada a través de elementos no verbales como los colores y las imágenes de recursos naturales y el uso de géneros musicales asociados históricamente a la alegría, y verbales como las letras de las canciones que invitan a dejar el conflicto atrás, exaltando la riqueza y diversidad) y la representación de la realidad violenta de la nación que ha enfrentado el conflicto (presente en las letras de la mayoría de las canciones que hablan de hechos o fenómenos de violencia).

Este conflicto de representaciones responde a la paradoja que encarnan todos los productos de memoria construidos por comisiones de verdad como el $\mathrm{CNMH}$, cuyo objetivo es contribuir a la construcción de la verdad del conflicto y ayudar a la no repetición y a la construcción de un futuro no violento en comunidad.

Las representaciones de memoria. Una de las principales consecuencias de las múltiples representaciones de memoria presentes en Tocó cantar es la complejización del discurso más ampliamente difundido sobre el conflicto armado, que les atribuye al odio y al fratricidio su existencia y que no profundiza en las razones estructurales económicas, sociales y políticas que lo alimentan. A pesar de que en el disco hay canciones que refuerzan este discurso, también existen otras que profundizan en las causas estructurales, nombran a los responsables y amplían la definición de conceptos como víctima, victimario y temporalidad del conflicto armado.

Las representaciones de resistencia. A pesar de que algunas de estas se encuentran presentes en las letras de las canciones, considero que las más importantes y tal vez las más invisibilizadas dentro del compilado son las prácticas artísticas locales de resistencia. Resistir desde la música no solo está asociado al producto sonoro, sino a la práctica que cumple una función en un contexto local determinado. 


\section{RECOMENDACIONES}

En esta sección, quiero resaltar la importancia de tener cuenta las particularidades, los recursos y los tiempos que implica realizar un objeto de memoria a través de la música como Tocó cantar.

Primero, es importante preguntarse por las formas de representación y la agencia de los diferentes actores involucrados en la realización del compilado. Considerando que el resultado de este proyecto no es solo un producto sonoro, sino la recolección de memoria de un evento o fenómeno de violencia de un individuo o un grupo, los autores de las canciones deberían participar en todas las etapas de desarrollo del disco y decidir cómo quieren ser representados. A pesar de que ellos tuvieron control sobre las letras de sus canciones (la dimensión sonora verbal), debido a que los tiempos para realizar la producción fueron muy cortos, no pudieron participar en el proceso de mezcla de sus canciones o en el diseño del contenido del cuadernillo (la dimensión sonora no verbal y visual). Todas estas dimensiones, como se evidenció en los grupos focales, cumplen un papel fundamental en la construcción de las representaciones, del sentido y de la recepción del compilado.

Segundo, considero que es fundamental hacer una proyección de las posibilidades reales de difusión y alcance del compilado desde la planeación del proyecto compartida con los ganadores o participantes desde el principio, para evitar generar expectativas que no se van a cumplir.

Finalmente, estimo que es fundamental que dentro de estos proyectos se contemple una etapa de retroalimentación, en la que participen todos los actores involucrados. El objetivo de estos proyectos no debe ser solo la entrega de un objeto, sonoro en este caso particular, sino generar aprendizaje sobre cómo hacer proyectos artísticos de recolección de memoria cada vez más responsables, incluyentes, dialogantes y críticos.

\section{NOTAS}

1. En este enlace http://www.centrodememoriahistorica.gov.co/discografia-toco-cantar se puede descargar el librillo con las letras del compilado y acceder a la lista de reproducción de SoundCloud donde se encuentran los audios de las cuarenta y cinco canciones.

2. Al no ser necesario presentar un certificado de víctima, los ganadores de la convocatoria tenían relaciones diferentes con el conflicto armado. Es importante aclarar que la catalogación de las letras fue hecha a partir del análisis de su contenido y no necesariamente da cuenta de la relación de los autores con el evento narrado en ellas. 


\section{REFERENCIAS}

Angulo, Nuris Oneyda. "No más abuso." En Tocó cantar: una travesía contra el olvido. CNMH. 2015.

Barbero, Alicia. 2005. "La activación de la imagen del enemigo y las nuevas guerras". Papeles de Cuestiones Internacionales 90:65-71.

Cabanerio, Ricardo. “De la guerra a la paz". En Tocó cantar: una travesía contra el olvido. CNMH. 2015.

Cano, José Ancizar. "Masacre en la Sonora". En Tocó cantar: una travesía contra el olvido. CNMH. 2015.

CNMH (Centro Nacional de Memorias Histórica). 2011. Las voces de El Salado.Bogotá: CNMH.

- 2014. Cantos del Carare. Bogotá: CNMH.

- 2015a. Las musas de Pogue. Bogotá: CNMH.

- 2015b. Tocó cantar: una travesía contra el olvido. Bogotá: CNMH.

Fry, Douglas P., Kaj Bj y Kaj Bjorkqvist. 2013. Cultural Variation in Conflict Resolution: Alternatives to Violence. Nueva York, EE. UU.: Psychology Press.

Fundación Chasquis. 2013. Les voy a cantar la historia: un viaje de retorno a la tierra. Bogotá: CNMH.

Hernández Salgar, Oscar Andrés. 2016. “Los mitos de la música nacional. Poder y emoción en las músicas populares colombianas 1930-1960". Tesis doctoral, Pontificia Universidad Javeriana. Consultado: 30 de mayo de 2019: https://repository.javeriana.edu.co/handle/10554/15410

Ley 1448/2011, de junio 10, por la cual se dictan medidas de atención, asistencia y reparación integral a las víctimas del conflicto armado interno y se dictan otras disposiciones.

Murry Murri, Yajaira. “Mu embera wera." En Tocó cantar: una travesía contra el olvido. CNMH. 2015.

Naranjo, Carlos Andrés. 2019. "Colombia: hacia una marca país competitiva". Naranjo Publicidad. Consultado el 30 de mayo de 2019: http://www.naranjopublicidad.com/tag/colombia/

Ritter, Jonathan. 2012. "Complementary Discourses of Truth and Memory: The Peruvian Truth Commission and the Canción Social Ayacuchana". En Music, Politics, and Violence, editado por John Morgan O'Connell y Salwa El-Shawan Castelo-Branco, 197-222. Wesleyan: Wesleyan University Press.

Turino, Thomas. 2014. "Peircean Thought as Core Theory for a Phenomenological Ethnomusicology". Ethnomusicology 58 (2): 185-221.

Wade, Peter. 2002. Música, raza y nación: música tropical en Colombia. Bogotá: Vicepresidencia de la República de Colombia. 